DARKO VIROVAC, M.Sc. ${ }^{1}$

E-mail: darko.virovac@croatiaairlines.hr ANITA DOMITROVIĆ, Ph.D. ${ }^{2}$

(Corresponding author)

E-mail: adomitrovic@fpz.hr

ERNEST BAZIJANAC, Ph.D. ${ }^{2}$

E-mail:ebazijanac@fpz.hr

${ }^{1}$ Croatia Airlines, Bani 75 b, Buzin, 10010 Zagreb, Croatia

2 University of Zagreb, Faculty of Transport and Traffic

Sciences, Vukelićeva 4, 10000 Zagreb, Croatia
Human - Transport Interaction

Original Scientific Paper

Submitted: 16 Feb. 2016

Accepted: 7 Apr. 2017

\title{
THE INFLUENCE OF HUMAN FACTOR IN AIRCRAFT MAINTENANCE
}

\begin{abstract}
Human factor is one of the safety barriers which is used in order to prevent accidents or incidents of aircraft. Therefore, the question is to which extent the error caused by human factor is included into the share of errors that are made during aircraft maintenance. In the EASA approved aircraft maintenance organisation, which includes in its working system the human factor as well, the tendency is to apply the approach by continuous monitoring and analysis of errors in aircraft maintenance. Such approach achieves advance prevention or reduction of the occurrence of harmful events, such as accidents, incidents, injuries and in a wider sense damages related to aircraft operation and maintenance. The research presented in this paper is a result of gathering and systematization of errors caused by human factors over the last five years in one organisation for aircraft maintenance certified according to the European standards. The study encompasses an analysis of 28 (twenty-eight) investigations of individual cases and provides insight into the main factors of errors. The results of analyses on the cause of occurrence of human error show similar results like the Boeing study which was carried out for the world fleet.
\end{abstract}

\section{KEY WORDS}

human factor; error analysis; aircraft maintenance; safety; monitoring; operative flying;

\section{INTRODUCTION}

Unintentional human errors in aircraft maintenance occur all the time. The branch dealing with this issue is called the Human Factor. According to the definition human factor is an unintentional error in the work which results in immediate damage of the system or it may be a hidden error which represents a potential danger for the technical airworthiness of the aircraft.

For a long time the Human Factor had been treated as a branch of ergonometry and exclusively as part of medical research. More detailed analyses have led to the knowledge that it is necessary to study the in terrelation of people, machines, environment and the production process. Human is the key factor in the production process and in the process of operation of technical means since it gives new value to the object of work. As a factor, the human is not perfect and introduces unintentional error in the system. It is important to develop a system of error identification and to work constantly on error prevention.

By studying the literature one may notice an increase in the interest for the analysis of human error in operation and maintenance of technical means in various transport branches. In paper [1], some of the important aspects of human performance of relevance to the traffic engineering are reviewed. These aspects include information processing, visual characteristics and information needs. According to paper [2] approximately $80 \%$ of marine casualties have root causes in human and organisational elements. The vast majority of these accidents occur during system operations. Paper [3] is based on the forty rail safety investigation reports that were reviewed and a theoretical framework under the title "Human Factors Analysis and Classification System" were adopted as a means of identifying errors associated with rail accidents/incidents in Australia. It was discovered that nearly half of the incidents resulted from an equipment failure, most of these the product of inadequate maintenance or monitoring programs.

This paper presents the influence of human factor in one of the European aircraft maintenance organisations for commercial service wide-body aircraft. Safety system has been implemented in the monitored aircraft maintenance organisation approved by the European Aviation Safety Agency (EASA). The safety policy statement is defined in the maintenance organisation and it is signed by the responsible person for organisation management (accountable manager). The safety policy is fully applied in accordance with the ICAO document "Human Factor Guidelines for Aircraft Maintenance Manual” (Doc 9859-AN/474). The highlight of maintenance safety policy in aviation is non-punitive reporting system which means that no action will be taken against any employee who 
discloses a safety concern through the hazard reporting system, unless such disclosure indicates, beyond any responsible doubt, an illegal act, gross negligence, or a deliberate disregard of regulations or procedures.

\section{UNINTENTIONAL HUMAN ERROR IN AIRCRAFT MAINTENANCE}

The works and activities on aircraft maintenance can produce hidden and active errors on the aircraft. Hidden errors are a type of errors that are seemingly invisible during aircraft flying. They themselves do not pose a threat, but in combination with other unfavourable incentive events or in combination with other errors may jeopardize the safety of aircraft operation. Active errors are errors that occur immediately and result in immediate aircraft damage or injury to people.

According to Eurocontrol document [4] and ICAO document [5] there is a visible trend of decline in the impact of human error in aircraft maintenance if one acts proactively on its elimination, Figure 1.

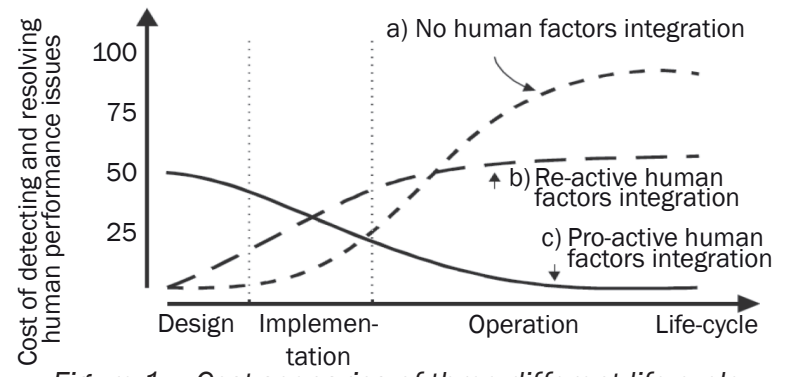

Figure 1 - Cost scenarios of three different life-cycle strategies

As shown in the diagram, there is a trend of increase in the human error if no model of elimination is implemented. With proactive action i.e. study of the cause of errors and with preventive setting of safety systems the trend of error occurrence decreases.

In the field of aircraft maintenance a number of methods and tools for the identification of the causes of human error and its elimination have been developed.

\subsection{Maintenance Safety Action Program}

Maintenance Safety Action Program [5] has been developed as tools for the prevention and reduction of errors in aircraft maintenance caused by unintentional error of technical personnel. The program proposes the participation of all the immediate stakeholders included in the process of aircraft operation and maintenance. The basic characteristics of the program include:

- technical personnel must continuously work on the improvement of the quality of work,

- the culture of reporting about errors without punishing the personnel has been developed; when people are punished the errors are kept hidden.
- reporting in case that employees have any recommendation for improvement of work process in the way to prevent possible future error

- introduction of the program into an organisation for aircraft maintenance means fewer errors in maintenance, which results in increase of safety and reduction of costs.

The starting concept of implementing this program is the inclusion of all participants as active factors in identifying errors and their elimination, even in case of an error that could be expected or has just happened. In the observed company this program and safety system in maintenance have been implemented, but in spite of that some events occurred.

\subsection{Dirty dozen}

Gordon Dupont, an employee of Transport Canada, defined the causes of unintentional human error by classifying them into twelve causes or "The dirty dozen" [6]. The errors have been defined based on the study of the causes of errors in the process of maintenance. The analysis of the occurrence of these errors represents the platform for finding the protective mechanisms or barriers that prevent their generation. The protective barriers are at the engineering level, on the imperfection and personality of people and on the organizational level. By acting on a certain level, one acts on the other two as well, so that every corrective action regarding the prevention of error occurrence has to be considered in all three dimensions of activities. According to Dupont, the main causes of human errors are:

- Lack of communication;

- Complacency (assessment of work according to previous working experience);

- Lack of knowledge;

- Distraction;

- Lack of team work;

- Fatigue;

- Lack of resources (lack of materials and technological support);

- Pressure (on the work performer);

- Lack of assertiveness (lack of self-confidence or technical approach to work);

- Stress (working under pressure);

- Lack of awareness;

- Norms.

\subsection{Tools for systematization of single findings in error research}

In literature one encounters different tools for systematization and analysis of human errors. Most tools startfrom theanalysis of causes and consequences. The answers to the questions asked are obtained by looking at the documentation, interviews with employees, 
various analyses and technical, chemical, and other research methods. For investigation it is necessary to systematize the findings, and at the same time during the investigation one has to have a clear picture of the investigation flow and the flow of events.

For the events analysis a combination of Fishbone diagram and Maintenance Error and Decision Aid (MEDA) form was used. The Fishbone diagram is standard investigation tool used for rhw analysis of the main factors and contributing factors which caused the event. MEDA investigation is adopted to investigate the main contributing factors caused by human factors.

\subsubsection{Fishbone diagram}

The fishbone diagram, the diagram of cause and consequence, or "Ishikawa diagram" [7] is a wellknown tools used for the control systematization and study of errors which have brought to the cause of irregularity. When designing the diagram the questions are used that search for the causes of problems and the cause and answer to the question are arranged on an adequate "bone". The questions of causes are asked by the research team until a clear picture is obtained where the problem comes from. The fishbone diagram has five branches as presented in Figure 2:

- Environment - which refers to the space and place for work as well as the conditions of work;

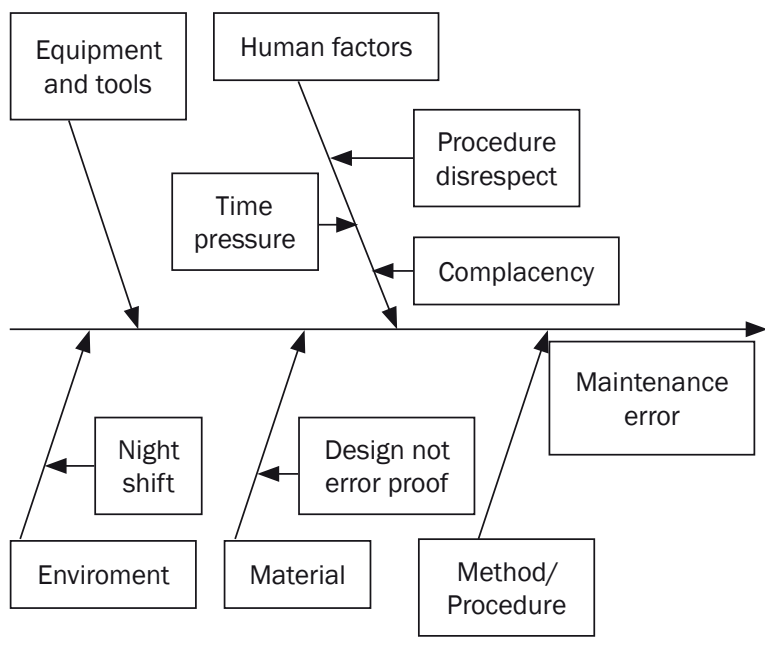

Figure 2 - Fishbone diagram

- Working process or method of work - which refers to the organisation of the working process, method of management and process flow;

- Material - which refers to the raw materials, components and the object of work;

- Equipment and tools - which are necessary in order to perform the work;

- Human factor - which refers to the cause of human error.
After determining the cause it is important to set the safety barriers that will prevent such an event from occurring in the future:

- at the level of the design of aircraft, tools and equipment that are used in aircraft maintenance;

- at the level of human factor through the improvement of the working process and conditions of work;

- at the level of company and company manage ment, education, change of norms, improvement of process and improvement in the management structure.

\subsubsection{Maintenance Error and Decision Aid Form (MEDA)}

In order to standardize the findings of the research in the aircraft maintenance system, Boeing has introduced a special form to test the errors in aircraft maintenance entitled "Maintenance Error and Decision Aid (MEDA)" [8]. The form is used in the system of error reporting in aircraft maintenance in order to act preventively and as aid to report an error when the error occurs. There are improvements in relation to the Fishbone diagram, since it simplifies the categorisation of the findings with implementation concretely on aircraft maintenance, thus making the comparison easier and clearer. MEDA Form has three important sections, as presented in Table 1. Each section has additional items or classifications which explain in more detail certain main divisions marked by capital letters.

One of the most important tools for the investigation process is the interview with employee whose performance leads to the event. Investigation process by MEDIA is part of organisation's behaviours.

\section{THE IMPACT OF HUMAN ERROR IN AIRCRAFT MAINTENANCE ORGANISATION}

\subsection{Conditions of study}

The study presented in this paper has analysed the errors that occurred during aircraft maintenance over a period of five years [9]. Only events that happened were used to be compared with the data analysed by other authors. The analysis included the cases of technical faultiness of aircraft that were reported in the written form as technical failures in aircraft maintenance, i.e. events that resulted from unintentional human error for whose occurrence several factors were determined. A total of 28 events were analysed. For every event an event analysis has been made within the organisation for technical maintenance of aircraft in which the event occurred and in accordance with good practice the measures for the elimination of factors that contributed to the error were undertaken. The research encompasses the level of aircraft tech- 
Table 1 - Classification according to MEDA Form

\begin{tabular}{|c|c|c|}
\hline Operative consequences on aircraft & Category of maintenance error & $\begin{array}{l}\text { Factors that lead to cause } \\
\text { of maintenance error }\end{array}$ \\
\hline $\begin{array}{l}\text { 1. Flight delay } \\
\text { 2. Flight cancellation } \\
\text { 3. Return from take off } \\
\text { 4. Engine stall in flight } \\
\text { 5. Return of aircraft after take off } \\
\text { 6. Diversion } \\
\text { 7. Damage to aircraft / equipment } \\
\text { 8. Injuries } \\
\text { 9. Repairs } \\
\text { 10. Other }\end{array}$ & $\begin{array}{l}\text { 1. Installation wrong or poor } \\
\text { 2. Poor servicing } \\
\text { 3. Bad/deficient repair } \\
\text { 4. Wrong error assessment / poor } \\
\text { inspection / bad testing } \\
\text { 5. Damage by foreign item during flight } \\
\text { 6. Damage caused by working equip- } \\
\text { ment } \\
\text { 7. Injury to people }\end{array}$ & $\begin{array}{l}\text { "A" information system of equipment } \\
\text { and aircraft manufacturer } \\
\text { "B" working equipment and tools } \\
\text { "C" design of aircraft, equipment and } \\
\text { parts } \\
\text { "D" working task } \\
\text { "E" technical education and level of } \\
\text { certification for work } \\
\text { "F" employee's personality } \\
\text { "G" working environment and logistics } \\
\text { "H" company organisation as factor } \\
\text { "I" working management and control } \\
\text { "J" communication }\end{array}$ \\
\hline
\end{tabular}

nical maintenance in line and base maintenance up to the level of annual inspections. The research has not included the workshop works which require special certification for the workshop operation. The observed time of performing works at the annual level is 365 days in a year in full-time hours which means day and night shifts. The research encompassed the aircraft of take-off mass higher than 5,700 kg and does not refer to helicopters.

\subsection{Analysis procedure of individual events}

In order to reduce the number of errors in aircraft maintenance, that are caused by human factor it is necessary to:

- establish a system of reporting the errors;

- establish a system that allows error analysis;

- in the analysis tors according to qualitative and quantitative principles;

- based on the obtained results to undertake corrective actions with the aim of reducing or completely eliminating the occurrence of error in maintenance.

Figure 3 presents the procedure of analysis of each case of error.

Procedure consists of the following steps:

1) Error report - the report can be obtained from the service user who notices the irregularity during operative flying. It may also be obtained from the aircraft inspection or from the auditor performing the audit. The most direct form of error reporting is from the employees participating in the maintenance process. Such reports are the indicators of positive working environment within the organisation

2) Investigation team for analysis - the team is formed at the request of the quality department. One member is from the quality department, and the other member is nominated according to the competence related to the nature of error. As nec-

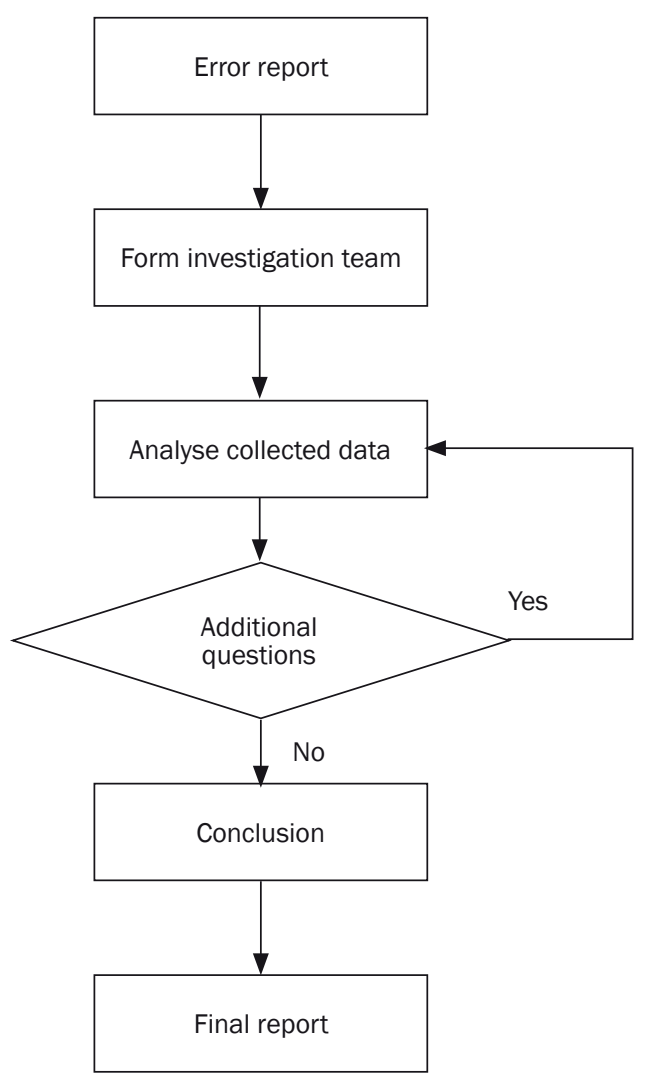

Figure 3 - Error analysis procedure

essary, other members can also join during the investigation.

3) Analysis of collected data - the analysis of event is done on the basis of the collected data. It is necessary to determine what happened and what the consequence of the event is. If there are uncertainties it is necessary to request explanation until every detail is clarified. It is necessary to determine the precise causes of error i.e. factors that led to the error, as well as the contributing factors that contributed to the error. 
4) Data collection - data used include: legal regulations, technical publications, written reports by event participants, employee's interviews, laboratory analyses, and other sources of information.

5) Conclusion - after finding out the cause of error it is necessary to systematize the data in order to eliminate the law of error occurrence. By knowing the factors that led to the error it is possible to find preventive strategies in order to prevent repeating of such or similar errors. The corrective measure has to be systematic and should not be based on punishing people or disrupting their reputation. The corrective measure must be such that the employees have the impression that the system is functioning in order to protect them and in order to improve their work.

6) Final report - the report must be published without the data that discover the identity of the person involved in the case. It is necessary for the employees to know what happened and what is being undertaken to avoid committing a similar error in the future. The basic aim of public disclosure has to be the education of employees and creation of a climate which allows active participation of employees in the detection and reporting on unintentional human errors in operation caused by human factor.

\subsection{Systematization of events}

After the analysis, the analysed events are systematized. The categorization of errors and causes of factors that contributed to error occurrence in the period of five years has been made according to MEDA Form, regarding the consequences that the error had on operative flying of the aircraft and the consequences in the system of aircraft technical maintenance. The basic principle in detecting an error in the system of aircraft technical maintenance is the asking of the question "what caused the error or what contributed to the occurrence of error?" The answer to this question represents at the same time the initial condition for the adoption of measures whose aim will be preventing similar errors in the future.

\section{RESULTS}

The chapter presents a result of the study of gathering and systematization of errors caused by human factors over the last five years in an organisation for aircraft maintenance certified according to the European aircraft maintenance standards. The study encompasses an analysis of 28 (twenty-eight) investigations of individual cases and provides insight into the main factors of errors [9]. The results of analyses on the cause of occurrence of human error show similar results like the Boeing study which was carried out for the world fleet [11].

According to the analysed events the errors that occurred in aircraft maintenance have been classified regarding different criteria, and the classifications are presented further in the paper [9].

There is no intention to describe the severity of event or mitigation requirements. The intention of the study is to compare the nature of events and its relative number with other studies in the world.

\subsection{Errors according to consequences that affect operative flying}

The errors in aircraft maintenance that had influence on operative flying are presented in Figure 4 . The first three most frequent errors in technical maintenance of aircraft are aircraft damage, aircraft delay in take-off and emergency repair of aircraft.

\subsection{Errors according to type of error}

According to the analysis of the mentioned errors in aircraft maintenance the errors have been classified in six categories that are presented in Figure 5.

The first three most frequent types of errors in aircraft maintenance are wrong installation of a part, failure in testing, and the third place is the inappropriately used working equipment and failures in servicing. The least expressed are the errors of aircraft damage which represent big material damage, and injury to people, which, although with least share of repetitions represent also the most tragic errors. The organisation for technical maintenance of aircraft should not have in its program of works the works that do not meet the criteria for the elimination of these two events.

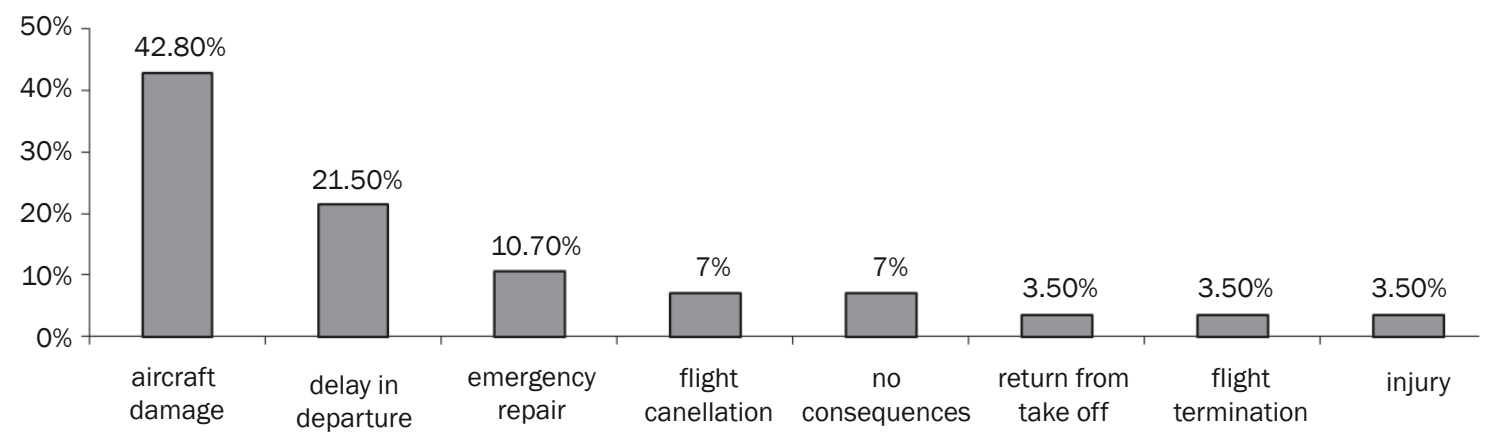

Figure 4 - Classification of errors according to consequences that affect operative flying 


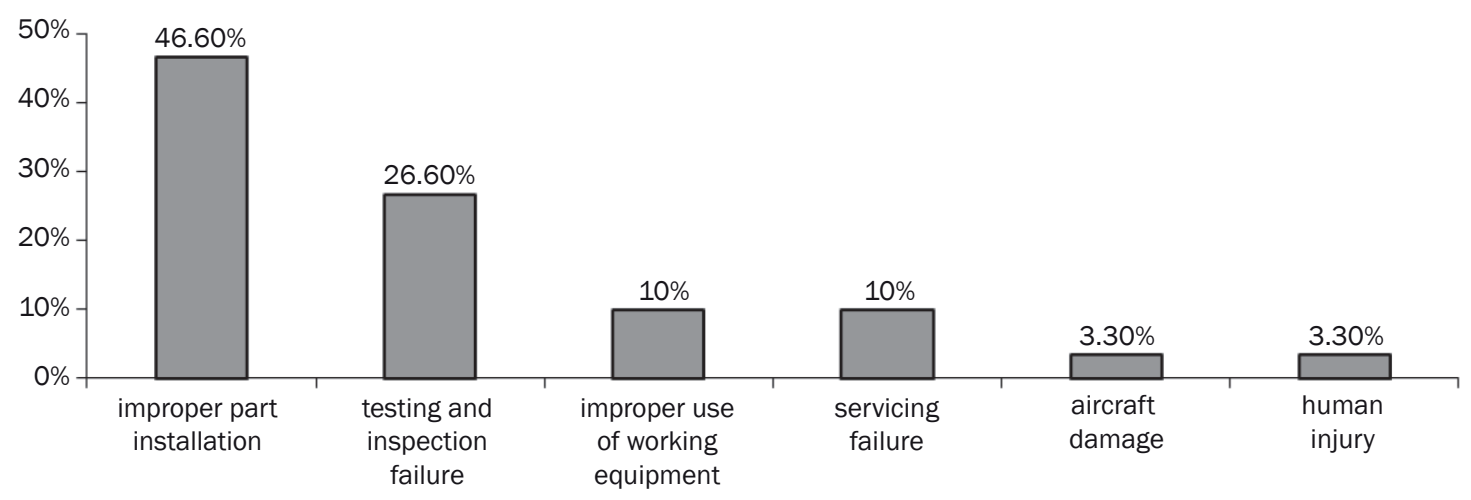

Figure 5 - Classification of errors according to type of error which occurs in aircraft maintenance

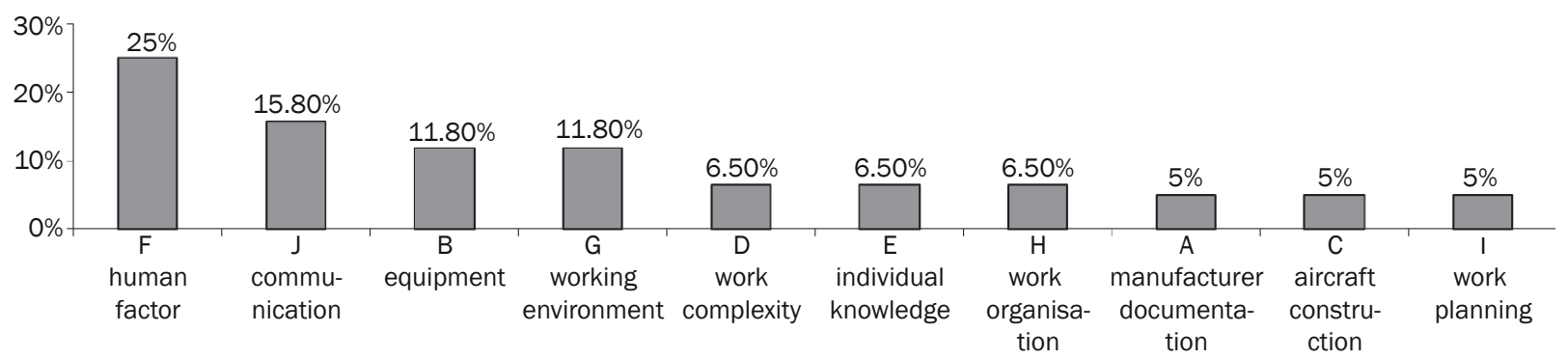

Figure 6 - Factors that contribute to error occurrence

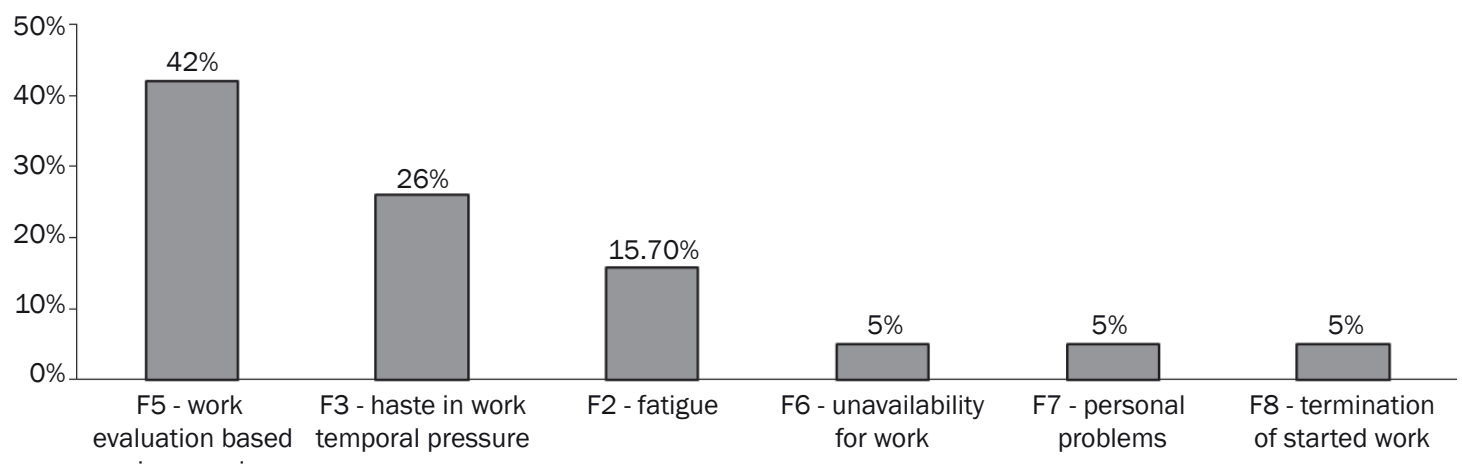

Figure 7 - Errors due to personality of individual

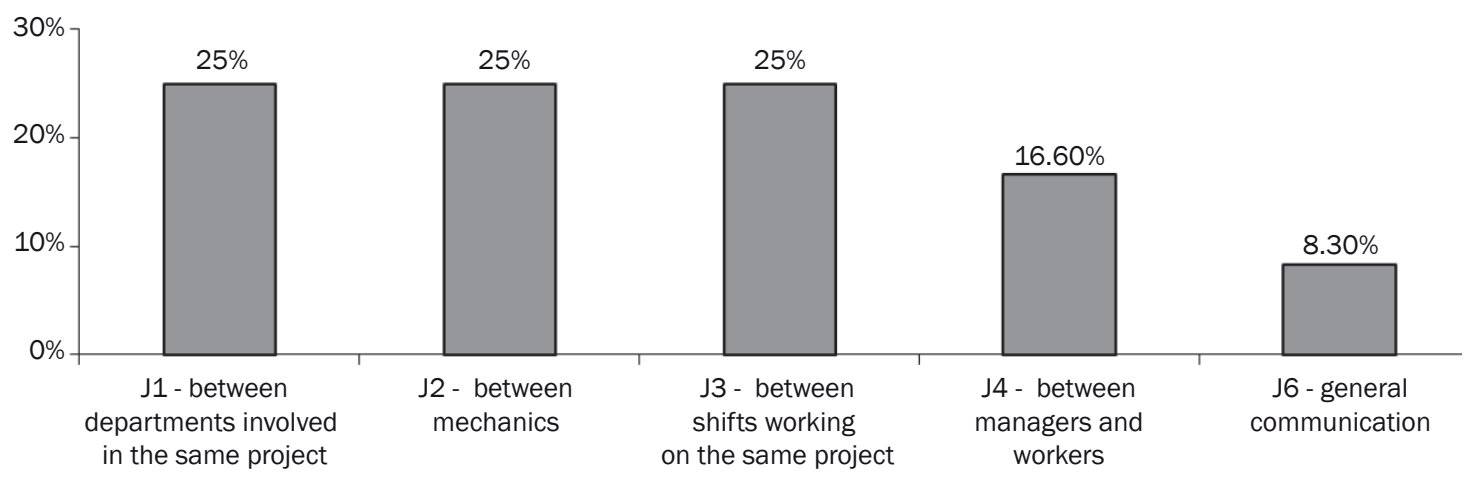

Figure 8 - Factor of communication 


\subsection{Factors that contribute to error occurrence}

Figure 6 shows the classification of error according to the factors that contribute to the occurrence of the error.

The classification is in compliance with the classification of Boeing, which is based on the breakdown determined by the MEDA Form. The first three factors that contributed to the error occurrence include: human factor, communication, and the third place is shared by the factors of equipment, tools and working environment. It is necessary to analyse in more detail the first three factors in the process of error occurrence.

\subsubsection{Individual's personality or human factor}

The classification of stimulating factors that cause unintentional human error or the human factor is presented in Figure 7 . The first three factors that contribute to error occurrence as part of observing the behaviour of unintentional errors of people are the estimate of work according to previous experience; the haste in work or time pressure, and the third in the row is fatigue. The basis to mitigate the mentioned factors is good planning of work regarding the volume of work, complexity and timeframe. In addition, it is necessary to work on continuous education of people in terms of warning about the errors in work and how to eliminate them. Less expressed factors from the personality of people are: unavailability for work, personal problems, and interruptions of the started work.

\subsubsection{Communication as factor contributing to error occurrence}

The classifications of stimulating factors that are causes of unintentional human errors caused by communication are presented in Figure 8. The graph analysis shows that the first three chains of communication are of equal intensity. To a minor percentage the problem of communication between the foremen and employees and the general communication system is expressed.

The first three factors include: communication among the departments involved in the project, communication among mechanics and the communication between the shifts that work on the same project. Such equal schedule indicates that the process or culture of communication is a systemic problem. In the production process the most critical is the transfer of information from the shift leaving work and the shift starting work. The critical link in the chain is the departure of the night shift when the employees are leaving tired. Then, there is usually noise in the communication channel since clear and complete messages fail to be conveyed. The conclusion is that it is necessary to standardize the messages and to educate the employees who use them.

The introduction of electronic communication is one of the systemic solutions. During the introduction of an operating computer system instead of the paper transmission of messages in the technical maintenance system, there has been great resistance by the elderly mechanics, and remarkable acceptance by the younger mechanics. In order to avoid negative effects since elderly generations felt inferior in relation to the younger ones, a systemic training, first of the elderly generation and then of the younger generation has been organized. A transition period of application was introduced until the system was accepted by the entire population. After introducing the electronic format of communication the volume of data and the transparency of work increased. The eligibility was complete by everyone. The system removed the monopoly or difficult availability of information which characterizes the paper system. Browsing, searching and selection of data enabled better communication among people. The system allows immediate informing of all the participants in the production process about the status of works and about the problems during the work.

\subsubsection{Equipment and tools}

The classification of errors regarding the usage of equipment and tools has been presented in Figure 9 . The usage of tools is related to the working culture and it is always in conjunction with the human factor. Having insight into the analysis one may see that as many as four factors are accounted for by $22 \%$ each in the total error, and these are: improper usage of tools,

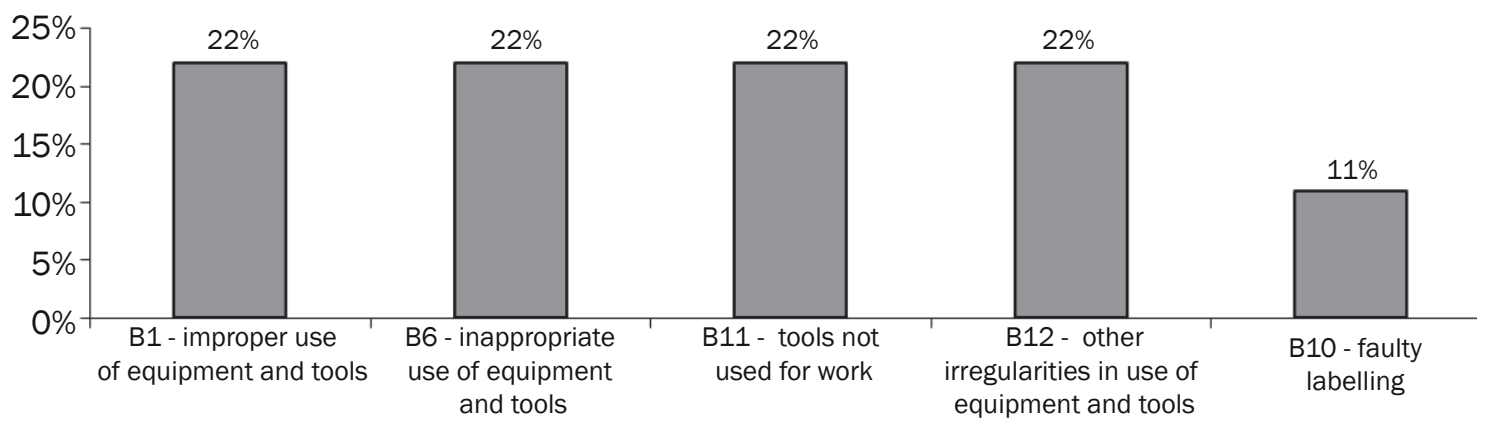

Figure 9 - Classification of errors regarding usage of equipment and tools 
using tools for wrong purposes, tools that are intended for work were not used, as well as other irregularities in the use of tools. The analysis indicates that such a balanced schedule represents the culture of using the tools within the technical system of maintenance.

Although the use of the equipment and the tools regarding the share of factors that contribute to the occurrence of error is on the third, i.e. fourth place on the ranking of events, they still represent an important factor with a share of $11.80 \%$ of influence on the error occurrence.

The preventive measure to reduce this factor is strong logistics, which means the design of a system which prevents the commencement of works without the tools that are taken for the work from the controlled environment, e.g. the tools storage. It is necessary to provide for all employees systemic training and reporting on every new tools or equipment that is purchased and included in the system for technical maintenance of aircraft.

The part which refers to improper designation of the tools is the part of internal procedures that have to be clearly defined and easy to understand for the employee. With permanent training and pointing to the failures in operation one may act qualitatively so as to reduce the problem to a minimum.

\subsection{Working environment}

Working environment affects greatly the competencies of the work of individuals and it is on the third i.e. fourth place regarding the share of factors that influence the occurrence of error. According to analysis, $89 \%$ of all factors is the influence of night work. Night work is according to the diagram the main generator of fatigue of employees in the technical aircraft maintenance. Nightshift of the technical maintenance related to operative flying has the task to bring the aircraft into the state of airworthiness. This means proper aircraft overhaul, performance of planned works, and work on errors that occur on the aircraft during operative flying. The issue of the duration of working and resting of the nightshift is the subject of scientific research.

According to [10] the impact of the environment on the working competencies of the humans has been studied. The focus is placed on resting of the employees working on aircraft maintenance in nightshifts.

A minor part in this analysis belongs to lighting. The amount of lighting necessary for work, according to type of work in the working conditions, is precisely prescribed. Moreover, the individual's characteristics, e.g. age, should also be taken into consideration. According to the ICAO recommendation the elder population of workers needs better lighting than the workers of younger population, in order to perform the same work with the same quality. Such situations require additional control of works done by the same worker after the completion of work or by another worker who was not a direct participant in the work.

\subsection{Other factors that contributed to error occurrence}

Other factors contributing to the error occurrence in aircraft maintenance are of the order of magnitude of $6.50 \%$ or less. These are: work complexity $(6.50 \%)$, knowledge of individuals (6.50\%), organisation of work (6.50\%), producer's documentation (5\%), aircraft design (5\%) and work planning. The total presence is with $34.5 \%$ of share. Although other factors are relatively low, they can have a significant share in error occurrence. These factors can be classified into two main groups, and these are: group that relies on the organisation which performs aircraft maintenance and part related to the manufacturer of equipment and aircraft.

The part which refers to aircraft maintenance is: complexity of work, knowledge of individuals, organisation of work and planning of work. These factors are interconnected and by influencing one you affect others as well.

\subsection{Comparison to similar studies in the world}

With the analysis of research described in this paper it is possible to compare the relation and cause of errors in aircraft maintenance with the errors that have been analysed in other similar studies. The comparison was made with the errors in the maintenance that was carried out by the Boeing Company, according to the program or error prevention in aircraft maintenance [11]. Tables 2, 3 and 4 contain comparisons according to previously described classifications.

Table 2 shows that according to Boeing data the first three consequences are: aircraft delay, aircraft damage and return from take-off. By analysing the research described in this paper the first three consequences on the operative capability of aircraft are: damage to aircraft, delay for flight, and emergency aircraft repairs. If this comparison included the factors that were presented in the previous analysis as less repeated, and these include flight cancellation (7\%), return from take-off (3.50\%) and aborted flight (3.5\%) one could see that the influence on operative aircraft flying was a total of $35 \%$ of events. This means that according to this research every third error during aircraft maintenance has direct impact on operative flying.

According to Table 3 the order of the first three factors in both analyses is the same, with the difference in the percentages of the share in the total distribution of the type of error in maintenance. According to Boeing data the first three types of technical errors in aircraft maintenance are: improper installation of a part, poor testing and poor overhaul. In the analysis of this research the first three types of technical error 
Table 2 - Impact of error in maintenance on the aircraft operative capability

\begin{tabular}{||c|c|c|c||}
\hline \multicolumn{4}{|c|}{ Operative consequences on aircraft } \\
\hline Analysis acc. to & I - in significance impact & II - in significance impact & III - in significance impact \\
\hline \hline Boeing & Aircraft delay & Aircraft damage & $\begin{array}{c}\text { Return of aircraft from } \\
\text { take-off } \\
15 \%\end{array}$ \\
\hline Aircraft maintenance & $30 \%$ & Damage to aircraft/ & Flight delay \\
organisation acc. to & equipment & $21 \%$ & $10.7 \%$ \\
European standards & $42.8 \%$ & & Repairs \\
\hline
\end{tabular}

Table 3 - Share of individual types of technical errors in maintenance

\begin{tabular}{||c|c|c|c||}
\hline \multicolumn{4}{|c|}{ Category of error in maintenance } \\
\hline Analysis acc. to & I - in significance impact & II - in significance impact & III - in significance impact \\
\hline \hline Boeing & Improper installation & Poor testing & Poor overhaul \\
& $35 \%$ & $15 \%$ & $12 \%$ \\
\hline & & & Poor overhaul \\
Aircraft maintenance & Improper or poor installation & Poor testing & $10 \%$ \\
organisation acc. to & $46.6 \%$ & $26.6 \%$ & Improperly used working \\
European standards & & & equipment \\
& & & $10 \%$ \\
\hline
\end{tabular}

Table 4 - Individual share of factors that contribute to the occurrence of human error

\begin{tabular}{||c|c|c|c||}
\hline \multicolumn{4}{|c|}{ Factors that contributed to human error in maintenance } \\
\hline Analysis acc. to & I - per significance & II - per significance & III - per significance \\
\hline \hline Boeing & Information & Communication & $\begin{array}{c}\text { Working environment/ } \\
\text { working task } \\
40 \%\end{array}$ \\
\hline Aircraft maintenance & $50 \%$ & $42 \%$ & Working environment \\
organisation acc. to & Employees' personality & Communication & $11.8 \%$ \\
European standards & $25 \%$ & $15.8 \%$ & $\begin{array}{c}\text { Equipment/tools } \\
11.8 \%\end{array}$ \\
\hline
\end{tabular}

in maintenance are: improper installation, poor testing and the third place is shared equally by poor overhaul and improper usage of equipment.

This indicates that the types of errors are similar regardless of the working environment. In order to have influence on the reduction of error and since they are at the same levels regarding significance, it is useful to study the solutions of other countries or organisations that have brought to the reduction of the mentioned errors. The organisations for aircraft maintenance should implement the mentioned solutions and adapt these to their working conditions in order to reduce the mentioned errors.

Table 4 shows that according to Boeing data the first three factors that have contributed to the occurrence of the error are: information, communication and working environment. In the analysis carried out in this research the first three factors that contributed to the occurrence of error are: employees' personality or human factor, communication, and the third place is shared by equipment, tools and the factor of working environment.
Although the results of these studies differ in several segments, it is obvious that the basic characteristics match regarding the place they occupy on the scale of occurrences. For proactive measures of protection for fighting error it is good to analyse every factor separately in the organisation for aircraft maintenance and to bring concrete measures for prevention that are appropriate for the company itself.

\section{CONCLUSION}

In aircraft-technical industry the bases on which the tendency is to reduce the number of unintentional human errors are levels in: modifications in aircraft design and tools, modifications in the program of acquiring the working and usage permits, introduction of obligatory education about human factor, consequences and method of eliminating the unintentional human error as well as continuous monitoring and analysis of human errors that occur. The legislative regulation for aircraft maintenance stipulates the obligatory control and supervising mechanisms of monitoring 
unintentional human error as part of the safety systems of technical proper functioning of aircraft. Strict implementation of these regulations and setting the aircraft maintenance organisation structure according to precise requirements of the regulations do not reduce the number and do not solve the problem of occurrence of unintentional human error in technical maintenance of aircraft in satisfactory amounts. In order to reduce significantly the number of unintentional human errors it is necessary to create a working climate within the technical organisation for aircraft maintenance, that will be stimulating for work and at the same time act preventively on the reduction of human error.

There is no unique method of implementing the abovementioned structure and method of realizing the proactive culture of work. This paper has presented the program of monitoring and analysing the impact of human error in aircraft maintenance.

Such and similar programs should be accepted and emphasised by the regulatory authorities since they are part of the working method of the organisation for aircraft maintenance and have direct impact on the technical functioning of the aircraft. At the same time these programs ensure quantitative and qualitative flow of the process of aircraft operation and maintenance. With the systematization and analysis of the obtained indicators one can act preventively on the process and people in order to reduce the errors in technical maintenance of aircraft.

\section{Mr. Sc. DARKO VIROVAC ${ }^{1}$}

E-mail: darko.virovac@croatiaairlines.hr

Doc. dr. Sc. ANITA DOMITROVIĆ ${ }^{2}$

E-mail: adomitrovic@fpz.hr

Prof. dr. sc. ERNEST BAZIJANAC, Ph.D. ${ }^{2}$

E-mail:ebazijanac@fpz.hr

${ }^{1}$ Croatia Airlines, Bani 75 b, Buzin,

10010 Zagreb, Hrvatska

${ }^{2}$ Sveučilište u Zagrebu, Fakultet prometnih znanosti

Vukelićeva 4, 10000 Zagreb, Hrvatska

\section{UTJECAJ LJUDSKOG ČIMBENIKA U ODRŽAVANJU ZRAKOPLOVA}

\section{SAŽETAK}

Ljudski čimbenik je jedna od sigurnosnih brana koja se koristi u cilju sprečavanja nesreća ili nezgoda zrakoplova. Zbog toga se postavlja pitanje u kojoj mjeri je greška uzrokovana ljudskim čimbenikom uključena u udio grešaka koje se učine u održavanju zrakoplova? U organizaciji za održavanje zrakoplova odobrenoj od EASA-e, koja uključuje u svoj sustav rada i ljudski čimbenik, pokušava se primijeniti pristup sa stalnim praćenjem i analizom grešaka u održavanju zrakoplova. Takvim pristupom postiže se unaprijed onemogućavanje ili smanjenje pojava štetnog događaja, kao što su nesreće, nezgode, povrede, i u širem pogledu štete vezane za održavanje i eksploataciju zrakoplova. U radu se daje prikaz istraživanja koje je rezultat prikupljanja i sistematiziranja grešaka uzrokovanih ljudskim čimbenikom u zadnjih pet godina u jednog organizaciji za održavanje zrakoplova. Istraživanje obuhvaća analizu 28 (dvadeset osam) istraga pojedinih slučajeva $i$ daje uvid u glavne čimbenike grešaka. Rezultati analiza o uzroku nastanka ljudske greške pokazuju slične rezultate kao i Boeingova studija koja je provedena za svjetsku flotu.

\section{KLUČNE RIJEČI}

ljudski čimbenik; analiza greške; održavanje zrakoplova;

\section{REFERENCES}

[1] Ogden KW. Human Factors in Traffic Engineering, ITE Journal. 1990 Aug;41-46.

[2] Švetak J. Human Factors in Marine Casualties. Promet - Traffic - Traffico. 2002;14(3):103-110.

[3] Baysari MT, Mclntosh AS, Wilson JR. Understanding the human factors contribution to railway accidents and incidents in Australia. Accident Analysis \& Prevention. 2008 Sep;40(5);1750-1757.

[4] Eurocontrol. Human Factors Module - A Business Case for Human Factors Investment. HUM.ET1. ST13.4000-REP-02. Ed. 1; 1999.

[5] ICAO. Human Factor Guidelines for Aircraft Maintenance Manual. Doc 9824-AN/450. Montreal; Manchester: International Civil Aviation Organisation; 2003.

[6] Federal Aviation Administration. Aviation Safety Action Program (ASAP). Advisory Circular No-120-66B; 2002. Federal Aviation Administration. Aviation Maintenance Technician Handbook - General, Chapter 14: Human Factors. Available from: http://www.faa.gov/regulations_policies/handbooks_manuals/aircraft/media/ AMT_Handbook_Addendum_Human_Factors.pdf [Accessed Sep 2013]

[7] Ishikawa K. Guide to Quality Control. Tokyo, Japan: Asian Productivity Organisation; 1986.

[8] Rankin W. MEDA Investigation Process. Boeing Aeromagazine. 2007;Qtr02(26):15-21. Available from: http://www.boeing.com/commercial/aeromagazine/ articles/qtr_2_07/AERO_Q207_article3.pdf

[9] Virovac D. A proactive approach model for error reduction in aircraft technical maintenance [Master thesis]. Zagreb: University of Zagreb, Faculty of Transport and Traffic Sciences; 2010.

[10] Johnson WB, Mason F, Hall S, Watson J. Evaluation of aviation maintenance working environments, fatigue, and human performance; 2001. 44 p. Available from: https://www.faa.gov/about/initiatives/maintenance_hf/library/documents/media/human_factors_ maintenance/evaluation_of_aviation_maintenance_ working_environments.fatigue.and_human_performance.pdf

[11] Xavier AJ. Managing Human Factors in Aircraft Maintenance through a Performance Excellence Framework. Hill AFB, UT: Embry-Riddle Aeronautical University; Mar 2005. Available from: http://www.system-safety.com/ articles/Xavier\%20Thesis.pdf 